\title{
A Study on the Effect of Environmental Impact Assessment of High-rise Buildings in the Tokyo Metropolitan Area
}

\author{
— Toward Strategic Environmental Assessment ——
}

\author{
Atsushi NAGAOKA* and Sachihiko Harashina**
}

\begin{abstract}
Tokyo Metropolitan Government enforced an ordinance of Environmental Impact Assessment (EIA) in 1981. The ordinance prescribes 26 types of development projects including high-rise buildings as they are likely to cause significant adverse effects on the environment. On the other hand, the ordinance amended in 2002 to bring easing of restrictions. Most of the projects of highrise buildings have been exempt from the objects of the ordinance since then.

The study focuses on the effect of EIA of high-rise buildings. Firstly, we figured out the circumstances behind each amendment of the ordinance. Secondly, the current environmental quality of high-rise buildings in Tokyo central area is investigated. And some cases of the highrise building EIA projects are discussed to identify the influences of EIA to the original plans. Based on these examinations and analyses, we finally identified the points of the improvements of the current EIA ordinance of Tokyo.
\end{abstract}

JEL classification: Q51, Q56, R52, R58

Keywords: Environmental Impact Assessment, High-rise Buildings, Tokyo Metropolitan Area, Strategic Environmental Assessment, Urban Development, Land Use

\section{Introduction}

In these years, environmental issues are getting widespread attention in the world. The notion of sustainable development is the most important common recognition. To protect the environment, Environmental Impact Assessment (EIA) system is regarded as one of the efficient means. EIA system has been applied to development projects when they start just before. We recognize that the EIA ordinance of Tokyo is achieving a certain level of success to protect the environment in each one.

On the other hand, Tokyo has been experienced rapid and serious urbanization, and urban environment is degradated with many aspects. And even today urban congestion is still progressing. Tokyo's population is the world's densest : in the most heavily urbanized portion, namely Tokyo's 23 wards. The area size is about $621 \mathrm{~km}^{2}$. There are still many problems such as shortage of open and green spaces and difficulties of disaster prevention,

* Department of Environmental Science and Technology, Tokyo Institute of Technology, G5-9 Nagatsuta-cho, Midori-ku, Yokohama 226-8502, Japan

E-mail : anagaoka@ depe.titech.ac.jp

** Department of Environmental Science and Technology, Tokyo Institute of Technology, G5-9 Nagatsuta-cho, Midori-ku, Yokohama 226-8502, Japan

E-mail : sahara@depe.titech.ac.jp 


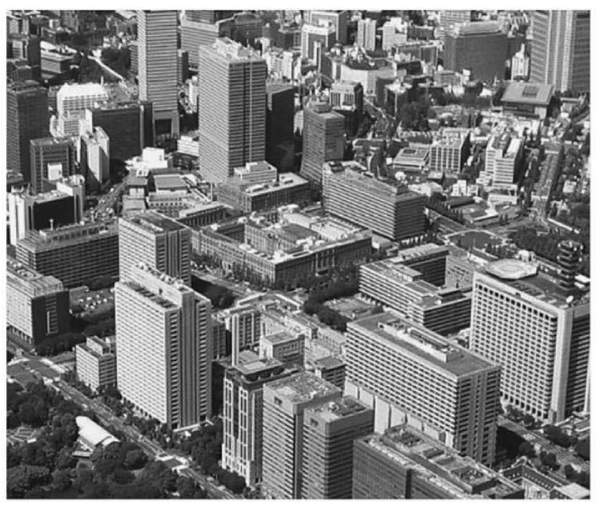

Tokyo

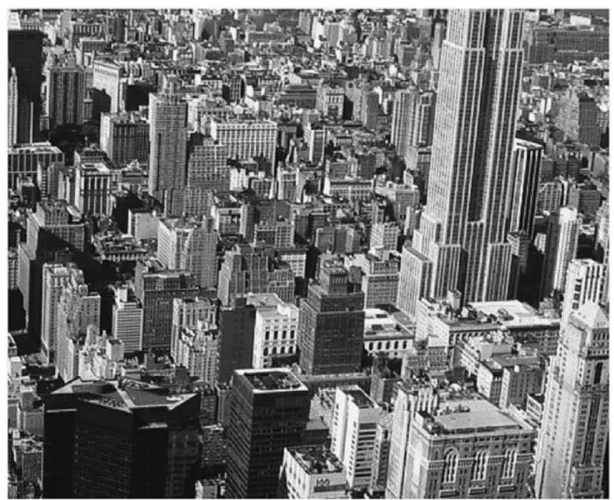

New York

The Central Business Districts

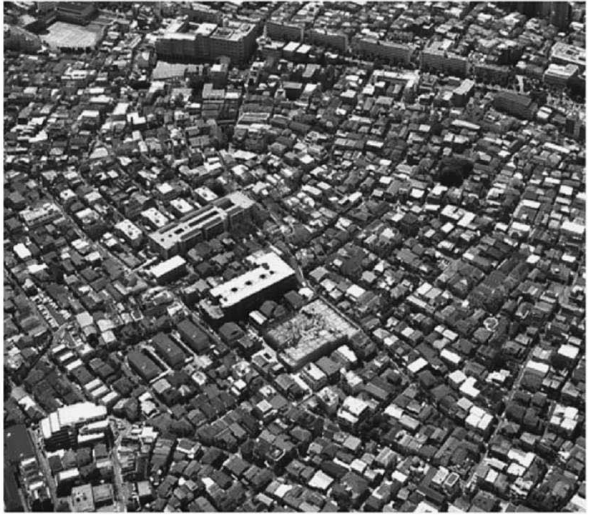

Tokyo

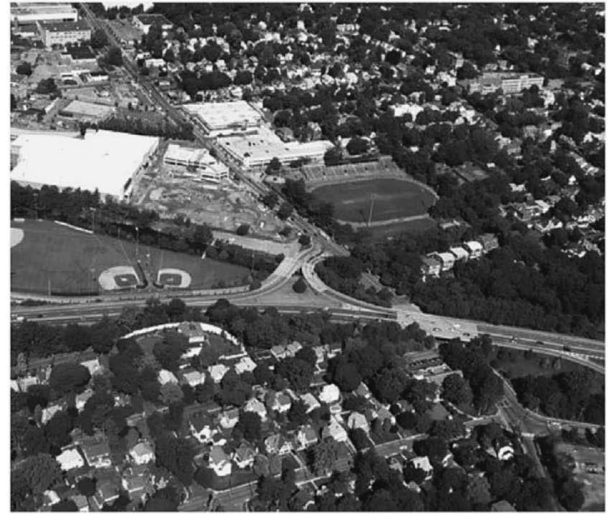

New York

$10 \mathrm{~km}$ from the CBDs

Figure 1 Land use patterns of Tokyo and New York (Photo by S. Harashina, 2004)

etc. In order to resolve these urban problems, we consider that land use planning is required. Figure 1 shows the urbanization of Tokyo compared to New York. The congestion of Tokyo is clear also from these photographs.

It might be true that the central part of New York City has more high-rise buildings than Tokyo, but at $10 \mathrm{~km}$, New York has far more open and green spaces than Tokyo. Given Tokyo's present state, it is clear that Tokyo needs land use controls to protect the people from disasters and improve the environmental quality.

The purpose of this research is to investigate how EIA ordinance in Tokyo has been influenced high-rise building projects' plan. The question which we must consider here is high-rise buildings have influence on the environment as they have risen markedly.

In what follows, we first grasp and investigate the enforcement and transition of Tokyo EIA ordinance. And we examine the present condition of high-rise buildings applied to the ordinance. Then we compare with some cases of the similar projects, which are not applied to the ordinance. Finally, we point out some issues and offer suggestions for improvements of the EIA system for sustainable development. 


\section{The EIA ordinance of Tokyo}

\subsection{Enforcement of the EIA ordinance of Tokyo Metropolis}

In Tokyo, many pollution problems related to industrialization had occurred from the 1960s to the 1970s. To resolve these problems, Tokyo Metropolitan Government (TMG) enforced the pollution control ordinance in 1969. After that time Tokyo environmental administration came to consider preventing environment problems before the implementation of development projects. In particular, such large-scale development projects as roads, housing areas, and waste landfill sites would have significant impacts on the environment in various aspects such as air pollution and soil contamination if they were implemented without any consideration for the environment. Furthermore by the change of social situation and the change in attitudes of Tokyo residents', Environmental Impact Assessment (EIA) system had come to be recognized.

Examination about introduction of EIA system was started from 1976. After a lot of discussions, TMG implemented EIA ordinance in October 1981. This ordinance prescribes 26 types of development projects including roads, railroads, urban development projects and high-rise buildings. In this study, we would like to focus attention on high-rise buildings with the ordinance. Because they have major impact on the environment, such as obstruc-

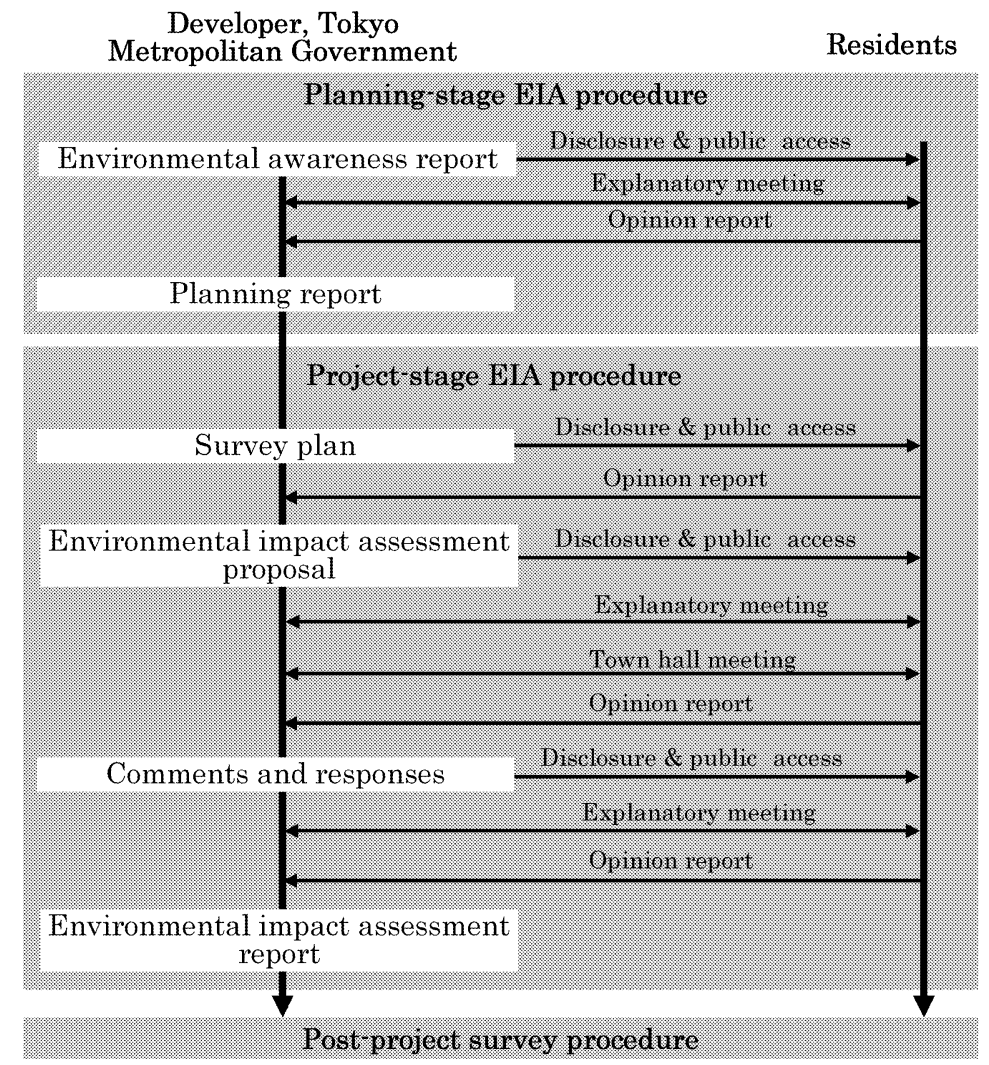

Figure 2 Procedure outline of Tokyo Metropolitan EIA Ordinance (Relation between Developer, Tokyo Metropolitan Government and Residents) 
Table 1 EIA Ordinance Forecast/evaluation items

\begin{tabular}{|c|c|c|c|}
\hline $\begin{array}{c}\text { Air pollution } \\
\text { Foul odor }\end{array}$ & Soil contamination & Access to sunlight & Opportunity for \\
Noise and & Soil foundation & Radio interference & interaction \\
vibration & Geographical \& & Wind circulation & Wastes \\
Water pollution & topographical features & View & Greenhouse \\
& Biological \& ecosystem & $\begin{array}{c}\text { Historic \& cultural } \\
\text { heritage }\end{array}$ & gases \\
\hline
\end{tabular}

Source: Tokyo Metropolitan Government 2005

tion of sunlight, radio disturbance, wind damage and landscape.

Then, the Japanese Diet passed the EIA Act in June 1997, which was fully implemented from 12 June 1999. TMG amended the ordinance in line with the EIA Act. In this TMG amendment, there are two revisions in large part. One would add the procedure of the "investigation plan document" equivalent to the "method document" in EIA Act, the other would add procedure related to the applied projects.

After that time, the ordinance was revised following points in July 2002. Those are addition of "Planning-stage EIA procedure", simplification of procedure in "Project-stage EIA procedure" and the name of "Public hearing" was changed into "Town hall meeting to hear opinions of Tokyo residents". By this change of the name, the reviewing committee members can participate in a town hall meeting and they can ask a question of witness. Enforcement of "Planning-stage EIA procedure" is in January 2003.

Figure 2 shows the current Procedure outline of Tokyo Metropolitan EIA Ordinance. Residents have several opportunities of participation to procedure by explanatory meeting, public access and town hall meeting.

Table 1 shows EIA ordinance forecast and evaluation items. They include access to sunlight, radio interference and wind circulation. Characteristic of Tokyo is succinctly expressed in these items. These are the typical examples of the impacts in metropolis. It is the result of taking into consideration the many overpopulated areas in Tokyo.

\subsection{Comprehensive Environmental Assessment System: The Semi-SEA of Tokyo Metropolis}

The Tokyo Ordinance of 1981 is EIA of individual projects. From this, we can derive the argument that the EIA ordinance has limitations to mitigate cumulative impacts caused by the projects and we have no way of changing or re-planning the project once started. This is to say that EIA is not the appropriate and effective measure to reduce cumulative and far-reaching environmental impact. To improve these defects, Necessity of Strategic Environmental Assessment (SEA) has come to be recognized. The approach of SEA is to provide for the application of EIA beyond individual development projects. TMG started to examine a kind of SEA system in autumn 1998. Called the Comprehensive Environmental Assessment System, it deals with comprehensive plans for regional development. The system has been introduced by revising the ordinance in 2002 .

This Semi-SEA of Tokyo, however, in terms of results, it was eased regulations in accordance with Japanese Governmental "Urban Renaissance” policy. Japanese Govern- 
Table 2 The number of development projects applied to the procedures of the EIA, Tokyo Metropolis

\begin{tabular}{|c|c|c|c|c|}
\hline \multirow[b]{2}{*}{ Types of Project } & \multirow{2}{*}{$\begin{array}{l}\text { Project-stage } \\
\text { EIA }\end{array}$} & \multirow{2}{*}{$\begin{array}{l}\text { Planning- } \\
\text { stage EIA }\end{array}$} & \multicolumn{2}{|c|}{$\begin{array}{c}\text { Numbers } \\
\text { (application stage) }\end{array}$} \\
\hline & & & $\begin{array}{l}\text { Tokyo } \\
\text { Metropolis } \\
\text { in total }\end{array}$ & $\begin{array}{c}\text { Tokyo } 23 \\
\text { wards } \\
\text { (central area) }\end{array}$ \\
\hline $\begin{array}{l}\text { Construction of housing } \\
\text { complexes }\end{array}$ & $\bigcirc$ & ○ & 33 & 14 \\
\hline $\begin{array}{l}\text { Construction of high-rise } \\
\text { buildings }\end{array}$ & O & & 35 & 35 \\
\hline $\begin{array}{l}\text { Construction or modification of } \\
\text { parking areas }\end{array}$ & O & $\bigcirc$ & 8 & 4 \\
\hline Land reorganization projects & O & O & 15 & 1 \\
\hline $\begin{array}{l}\text { Built-up area redevelopment } \\
\text { projects }\end{array}$ & O & O & 2 & 2 \\
\hline $\begin{array}{l}\text { Earthwork on land for building } \\
\text { projects }\end{array}$ & $\bigcirc$ & $\bigcirc$ & 8 & 0 \\
\hline
\end{tabular}

October in 1981-March in 2005

Source: Tokyo Metropolitan Government 2005

ment is pushing forth a sweeping relaxation of regulations such as City Planning Law and Building Standard Law. And Urban Renaissance Special Measure Law went into effect in June 2002. We understand that this policy aims at supporting economic activities by construction of many high-rise buildings in Tokyo. TMG followed the Government's policy. There are three eliminations of regulation from the EIA ordinance.

- "Specific areas" were established in the central part of Tokyo Metropolis. In these areas, altitudinal condition of high-rise building applied to the EIA was revised from over $100 \mathrm{~m}$ to over $180 \mathrm{~m}$, and gross floor space regulation was revised from 100,000 square meters to 150,000 square meters. Few buildings are applied to the EIA by this revision.

- In "Specific areas", developer can skip submission of the EIA Survey plan at the outset of the procedure.

- In all of Tokyo including "Specific areas", housing complex size and parking area size were eased regulations.

Refer to Figure 6 for "Specific areas". These are central areas of the business and the commercial in Tokyo. Actual achievement of main development projects are shown in Table 2. It appears that many development projects are localized in Tokyo 23 wards. All high-rise buildings are applied in particular. All development projects except high-rise buildings are the subject of Planning-stage EIA.

\subsection{Relativity of actual EIA ordinance and the City planning law}

EIA ordinance of Tokyo is composed of "Planning-stage procedure", "Project-stage procedure" and "Post-project survey procedure". Figure 3 shows the procedure of Tokyo Metropolitan EIA Ordinance and the City Planning Law.

EIA procedure is almost independent of City Planning Law procedure. Those proce- 


\section{Procedure under the Tokyo Metropolitan EIA Ordinance}

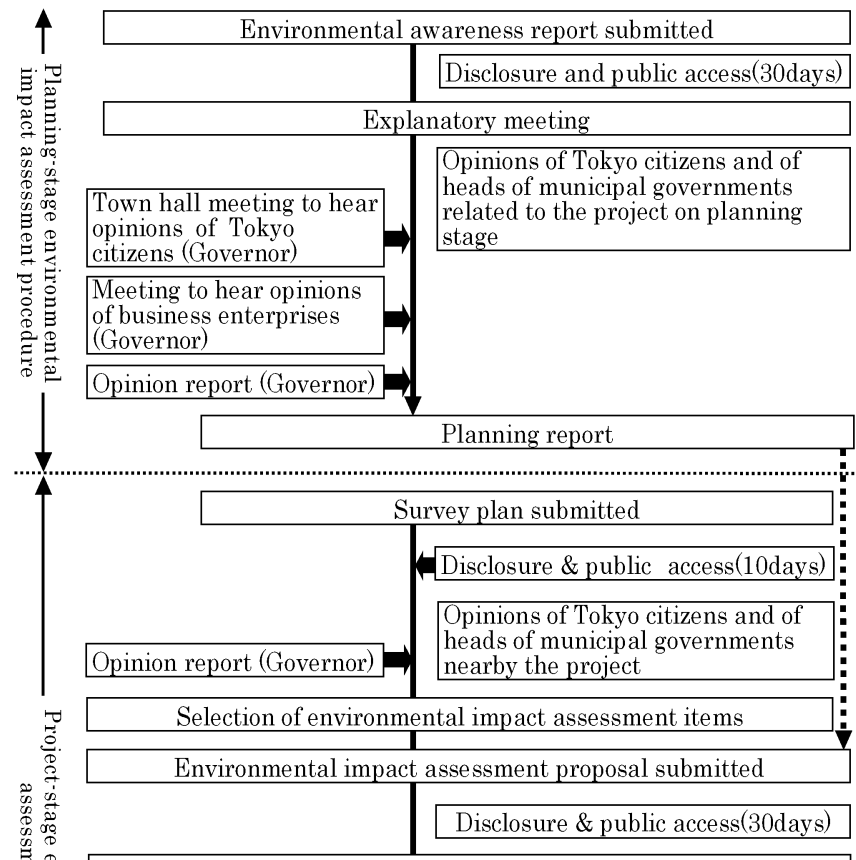

City Planning Law

(Tokyo Metropolitan Government decision)

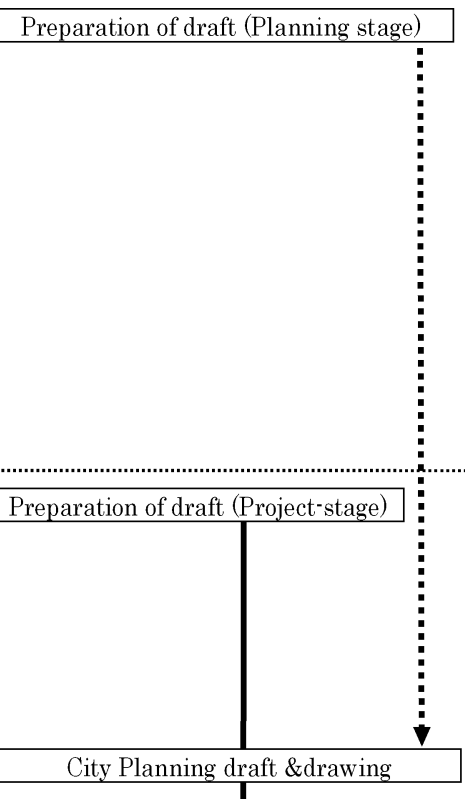

Minister of land, infrastructure and transportation prior consultation
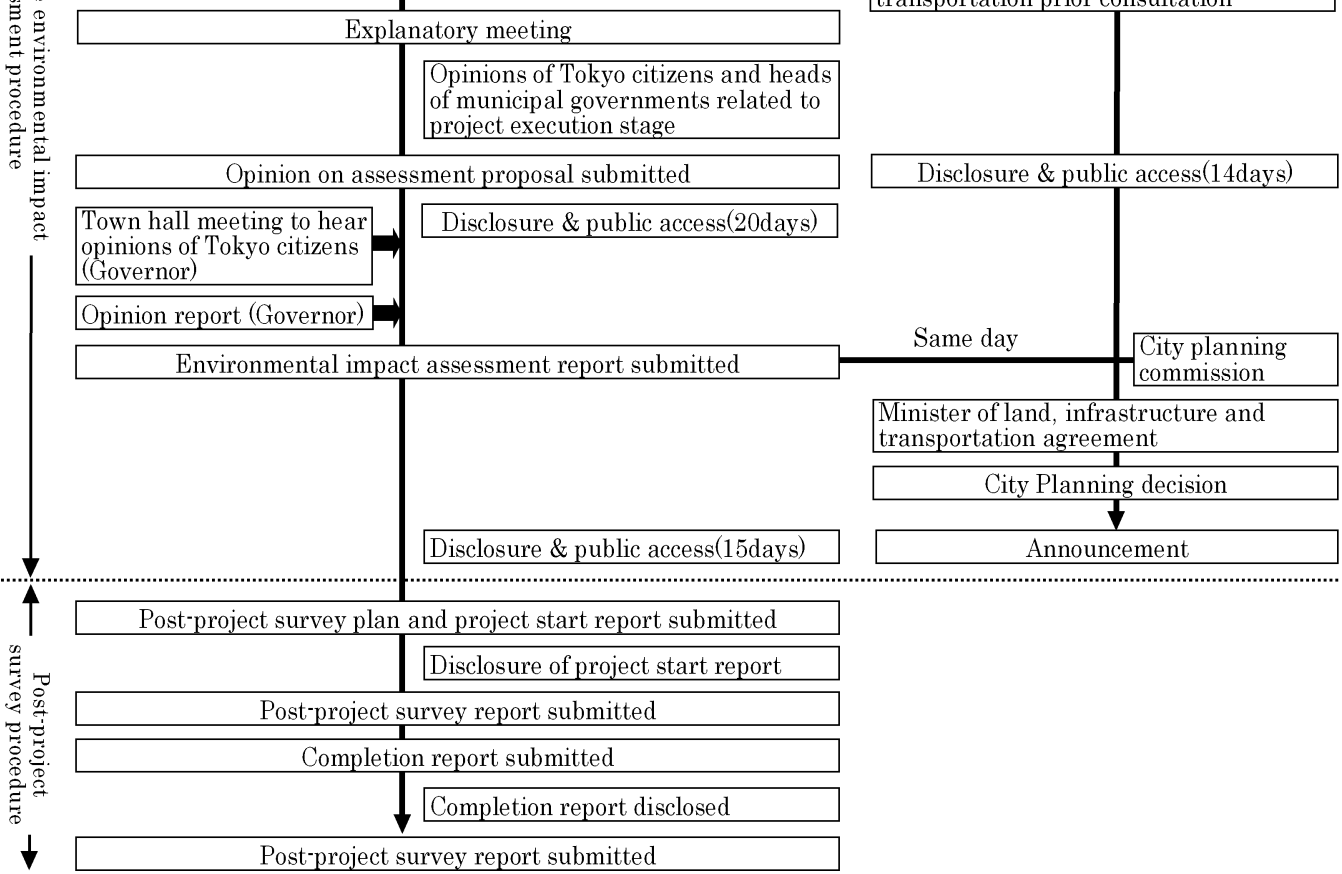

Figure 3 Tokyo Metropolitan EIA Ordinance and the City Planning Law 
dures have only one connection. To take account of the influence on urban environment of Tokyo, we consider that they should be dealt with from a comprehensive standpoint.

Furthermore "Planning-stage EIA procedure" is implemented only if the project proponent is the TMG. No private developer's projects are contained in the EIA system. In other words, all high-rise buildings projects are the procedure which begins from EIA procedure on "Project-stage". In fact, almost all high-rise buildings were not included in the EIA ordinance, though they kept increasing late years in Tokyo. By the Urban Renaissance Special Measure Law, though large-scale development projects are proceeding at a swift pace in many areas, it seemed reasonable to think that they are not applied to the ordinance. We would like to emphasize that there are serious problems from the viewpoint of environmental effectiveness.

\subsection{The features of the present EIA ordinance}

The features of Tokyo EIA ordinance are as follows, which are basically same other local ordinances in Japan.

1. Introduction of planning stage assessment

- Comparative assessment of a number of project plans from the environmental perspective, in the early stages of project planning

- Plan assessment is implemented if the project owner is only TMG

- Projects for which plan assessment has been implemented may omit a part of project assessment

2. Establishment of developer liability and assessment standards, etc., and organization of deliberative meetings

- Developers to be responsible and pay for surveying, forecasting and evaluation

- Establishment of technical indicators and ex post survey standards

- Establishment, in response to a call by the Governor of Tokyo, of the EIA reviewing committee for the purposes of investigating and reviewing issues pertaining to EIA, and conducting ex post facto studies from an expert standpoint

3. Improvement of the opportunities of participation

- Additional to the procedures of submitting opinions, public hearing meetings were modified to hear Tokyo residents' opinions more directly

4. Post project survey procedure

- Ex post study to investigate the state of implementation of environmental protection measures, during execution and after completion of projects

5. Assurance of effectiveness

- Request for attention to the authorities issuing permits and approvals related to operations, request for action toward business enterprises, etc.

\subsection{The EIA guideline of Minato ward}

Aside from Tokyo EIA ordinance, Minato Ward, which is located in the CBD area, had started the original EIA guideline in 1995. This is one of a few EIA guidelines among Tokyo 23 wards. This guideline targets high-rise buildings with the total floor space of 50,000 and over square meters (including parking area). Evaluation items of this guideline include 
characterized environmental impacts of high-rise buildings such as radio disturbance, sunlight impediment, and landscape. These follow the EIA ordinance of Tokyo. Development projects except from the EIA ordinance of Tokyo are applied to this guideline.

\section{High-rise buildings applied to the EIA ordinance of Tokyo}

\subsection{Actual status of high-rise buildings}

The construction of high-rise buildings has been increased rapidly by a series of eased regulations since the 1980s. Furthermore, the government, local municipality and business organizations have sold off many and large tracts of lands. Those lands have been devel-

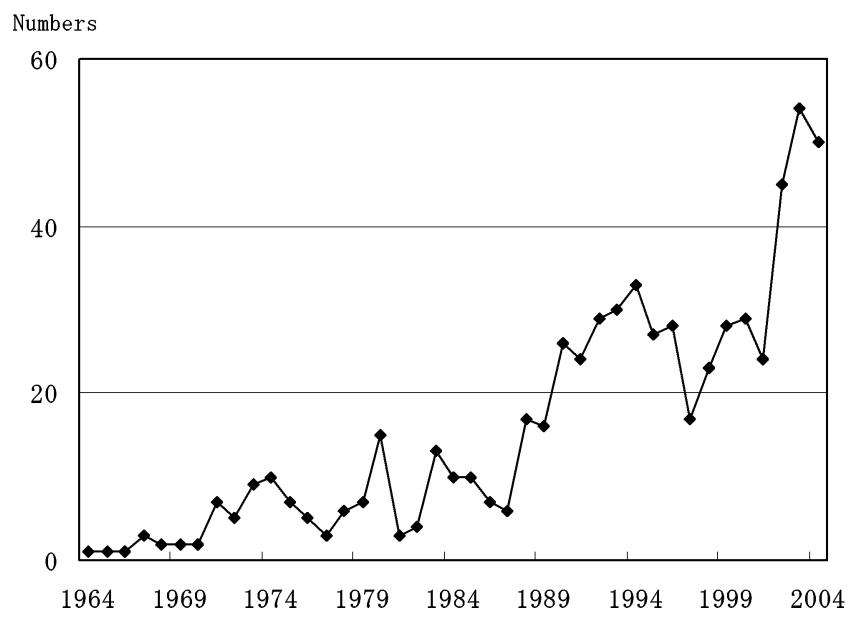

Figure 4 The number of high-rise buildings built each year in Tokyo 23 wards Source: Tokyo Metropolitan Government 2005

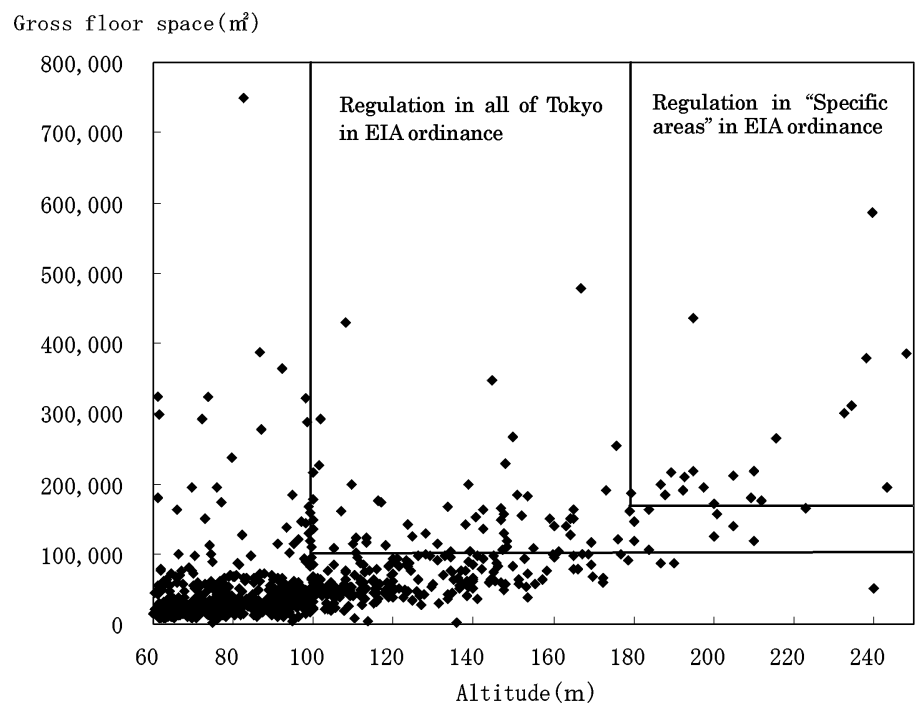

Figure 5 The relation between altitude and gross floor space of high-rise buildings in Tokyo 23 wards

Source: Tokyo Metropolitan Government 2005 
oped by many developers everywhere in the central part of Tokyo. Figure 4 shows the number of new construction of high-rise buildings ( $60 \mathrm{~m}$ or more) in Tokyo central area. By studying the plots on Figure 5 we can get a sense of relation between altitude and gross floor space. These indicate regulation coverage of EIA ordinance and there are not many.

\subsection{High-rise buildings to which the EIA ordinance applies}

High-rise buildings to which the EIA ordinance applies are 44 projects as of end-March

Table 3 EIA procedures of high-rise buildings, Tokyo Metropolis

\begin{tabular}{|l|c|}
\hline \multicolumn{1}{|c|}{ Implementation of the EIA ordinance } & Numbers \\
\hline Procedure completion & 13 \\
\hline Post-project survey & 17 \\
\hline Final EIA report & 8 \\
\hline Exempt from the subject by amended the ordinance & 1 \\
\hline Closing business & 1 \\
\hline Exempt from the subject by changing plan & 1 \\
\hline Business interruption & \\
\hline
\end{tabular}

October in 1981-March in 2005

Source: Tokyo Metropolitan Government 2005

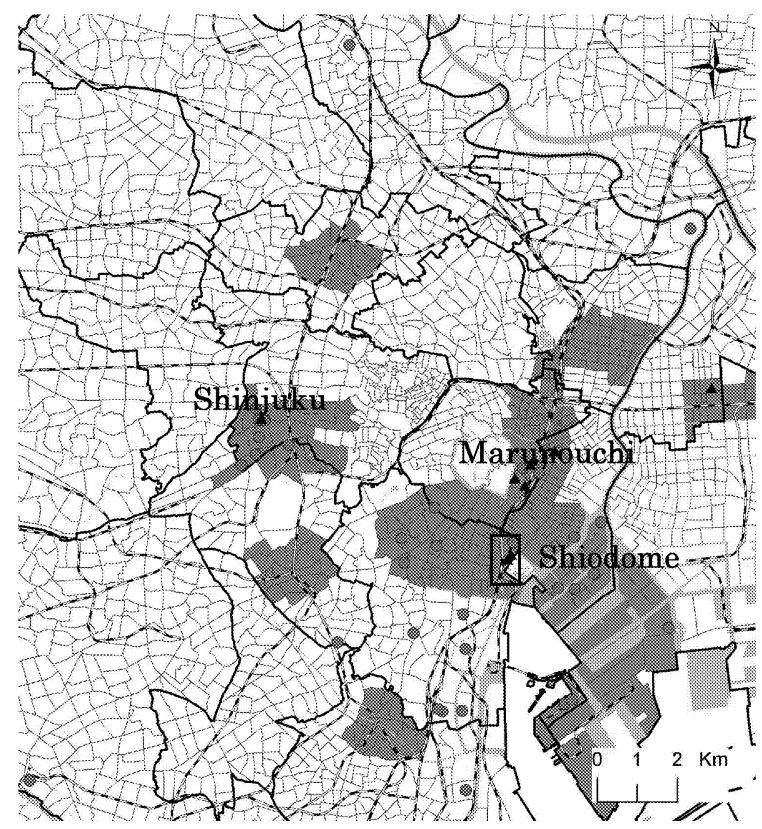

Figure 6 Locations which EIA ordinance applies to high-rise buildings, Tokyo Metropolis

- : Applied project

\ : Exempt project after the amendment the ordinance

Gray zone: "Specific areas" (Designation in response to Urban Renaissance Special Measure Law)

Source: Tokyo Metropolitan Government 2005 
in 2005. There are more than 200 high-rise buildings, whose heights are $100 \mathrm{~m}$ or more, in Tokyo 23 wards. The number of EIA is very small compared to that of present high-rise buildings. The current EIA procedure is shown in Table 3.

Figure 6 shows the locations of high-rise buildings to which EIA ordinance applies in the Tokyo central area. They are concentrated in the "Specific areas" such as Marunouchi, Shinjuku and Shiodome. For this reason, it would not be an exaggeration to say that most of them will not be applied to the EIA ordinance in the years ahead.

\subsection{The performance and problems}

The purpose of the ordinance is to examine and evaluate the influence to the environment caused by the development projects. In this process, business organizations disclose the information to the residents and the residents can express opinions. And business organizations are expected to take opinions of residents into their environmental consideration. Therefore project assessment doesn't hold authorization right of enterprise. We evaluate the following points that residents can express opinions two times from the early stages of the EIA process and business organizations could gather a wide range of residents' opinions. Under this ordinance, there are fixed effects in reduction of environmental impact.

On the one hand, increasing of high-rise buildings has caused many environmental and social problems in late years. We consider that it is because reform of regulations and systems can't sufficiently respond to increase of recent huge high-rise buildings. That's just one of the reasons several problems have revealed in large-scale developments by project assessment alone in EIA ordinance. Next, we give a typical example which is one of large redevelopment project in Tokyo.

\section{EIA ordinance applied to a large-scale development project - Case study on the Shiodome development area-}

\subsection{Development outline}

Nowadays, many huge and joint development projects are under way in the Tokyo central area. Those projects attribute to the policy of giving priority to large-scale development and change in social and economic conditions.

Shiodome project is one of the largest development project in these. The size of area dimensions is about 31 ha and consists of eleven development districts (Figure 7). This project consists of open spaces, office, hotel, commercial facilities, residence, and so forth. When the whole project is completed, the numbers of employees and residents are going to be sixty-one thousands and six thousands respectively. However, there were various arguments that surround influence on the environment and the way that should be of a plan. It was because the area was the rare land left behind in the central part of Tokyo.

\subsection{Implementation of the EIA ordinance}

The master plan of the project was made in the process of land readjustment project in TMG. Then community plan was carried out followed by the scheme. In development process, each EIA procedures have been conducted almost separately for each buildings. 


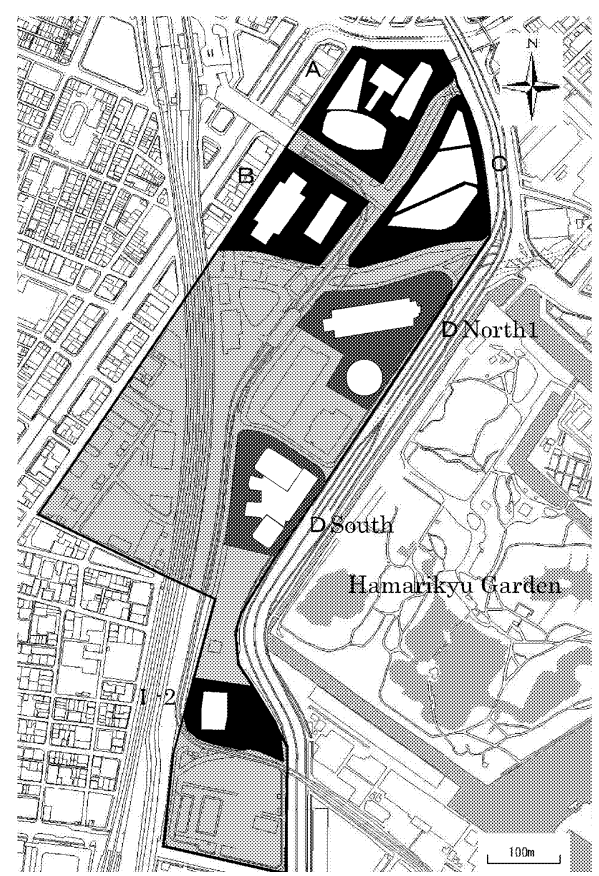

Figure 7 Shiodome development project

: Applied project of EIA

: Project stopped the EIA procedure on the way

Table 4 The conclusions in the EIA report for A, B, and C districts

\begin{tabular}{|c|c|}
\hline Noise & $\begin{array}{l}\text { Distracting noise during construction is below the environmental standard of Tokyo. } \\
\text { Cooling tower noise standard of area conditioning is } 42 \mathrm{~dB}(\mathrm{~A}) \text { in morning, daytime, } \\
\text { and evening, } 39 \mathrm{~dB}(\mathrm{~A}) \text { in night. These are less than environmental standard of } \\
\text { Tokyo. }\end{array}$ \\
\hline Vibration & $\begin{array}{l}\text { Road traffic vibration level is } 36-60 \mathrm{~dB}(\mathrm{~A}) \text { at a road end, and the increasing } \\
\text { vibration level is } 1 \mathrm{~dB} \text { or less. These are less than environmental standard of Tokyo. }\end{array}$ \\
\hline $\begin{array}{l}\text { Obstruct } \\
\text { sunlight }\end{array}$ & $\begin{array}{l}\text { Areas which exist in shadow zone over four hours by these projects are almost road } \\
\text { and office buildings. These areas which obstruct sunlight influences are very small. }\end{array}$ \\
\hline $\begin{array}{l}\text { Radio } \\
\text { interference }\end{array}$ & $\begin{array}{l}\text { Developers adopt proper alternate measures with radio interference. When the } \\
\text { obstacle becomes clear according to these projects, developers are supposed to take } \\
\text { appropriate measures immediately. }\end{array}$ \\
\hline Wind damage & $\begin{array}{l}\text { Wind damage by these projects is equal to business districts. Developers set planting, } \\
\text { monument and fence. By these measures, it should be considered within an allow- } \\
\text { ance. }\end{array}$ \\
\hline Landscape & These developments form new urban landscape of the surrounding areas. \\
\hline Historic place & $\begin{array}{l}\text { There is no direct influence by these constructions for Hamarikyu garden. Sunlight } \\
\text { impediment has not a direct influence and change of environment cannot be found. }\end{array}$ \\
\hline
\end{tabular}

In early stage of development planning, EIA procedure had been applied to five districts. Then, EIA procedures were eliminated at two districts by amendment the ordinance and revisions of development plan (D North 1, D South). In addition, there is one project applied to the Minato ward EIA guideline (I-2). 
From the beginning of development project, serious environmental problems had been pointed out. The effect on environment for districts $\mathrm{A}, \mathrm{B}$ and $\mathrm{C}$ was estimated as follows (Table 4). The EIA procedure was conducted for these districts as one procedure because of simultaneous and adjacent developments.

\subsection{Discussions of the development project}

Controversial issues which had become clear through the project EIA procedure and the opinions of Tokyo residents are as follows.

- Nitrogen dioxide exceeding environmental standard by concentration of future traffic density

- Noise prediction exceeding the environmental standard

- Strong winds blowing through the buildings

- Sunlight impediment from the buildings

- Fatal influence on the landscape of Hamarikyu Garden (A beautiful and historical Japanese Garden)

- The progress of urban heat island phenomenon

These problems had been pointed out in each assessment report and other examinations by the public. However, those plans were changed hardly at all. And districts A, B and C were completed. At the present day many development projects are being completed in other districts (Figure 8). These problems are obvious proofs which show the shortcomings of project EIA procedure. Moreover, cumulative impact is also becoming large as one development becomes large-scale. In a word, these problems were caused because the plan was fixed to begin with.

\section{Conclusions}

As mentioned above, the EIA ordinance of TMG has been applied to high-rise buildings from the outset of the ordinance enforcement. And during the EIA process, business organizations have incorporated relevant residents' opinions to some extent. We regard these points as limited success.

However, it seemed that project EIA alone has limitations to reduce the environmental impact as development project has becoming huge and complex in recent years. In addition,
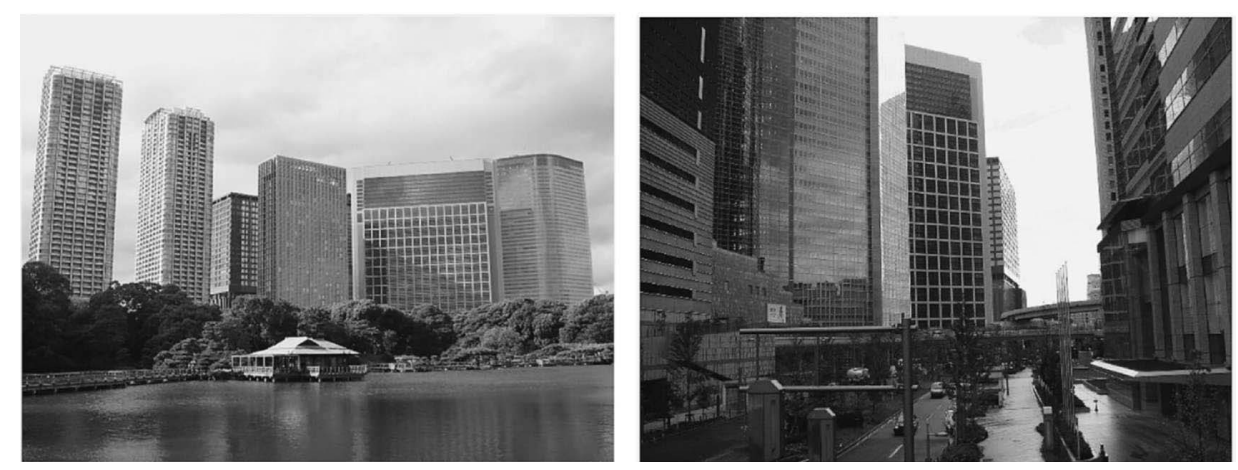

Figure 8 Developed Shiodome (Photo by A. Nagaoka) 
most of high-rise buildings will be left out of the ordinance by relaxation of the regulation in the coming years. Therefore, the effectiveness of the EIA ordinance should be decreased. The cumulative impacts of high-rise buildings are becoming larger. There are survey results $^{1,2}$ which clarify urban heat island phenomena caused by extreme urbanization in Tokyo.

It is particular importance in the light of discussions on how development projects and high-rise buildings should take place. We consider that the following points are required for the EIA system.

- When development projects are conducted at the same period and nearby, EIA procedure should consider mutual cumulative impacts.

- For taking the comprehensive influence on the environment into consideration, it is necessary to describe the land use planning in a more concrete form in the early planning process.

- It is required to consider community plan and EIA system from a comprehensive standpoint.

These lead also to the necessity for Strategic Environmental Assessment (SEA) system. Through SEA system, the study of alternative plans could be conducted from the beginning of the planning process. And the system can assess the cumulative impacts of individual development projects. SEA should be applied to the early decision-making at strategic levels in order to avoid the shortcomings of EIA system. It can be applied to a wide range of decision-making from legislative processes to city and regional planning for the future.

It, therefore, could be enabled that many aspects such as social and environmental impacts can be researched in all of Tokyo to realize sustainable development.

\section{References}

[1] Environmental impact assessment proposal, Receipt number 183, - Shiodome A, B, and C districts - (in Japanese), 1998.

[2 ] Environmental impact assessment report, Receipt number 183, - Shiodome A, B, and C districts(in Japanese), 1999.

[ 3 ] Institute for the study of Construction policy, Urban Renaissance breaks city (in Japanese), 2004.

[4] Japan Association of Environment Assessment, The history of Japan environmental assessment (in Japanese), 2003.

[5] Opinion on assessment proposal, Receipt number 183, - Shiodome A, B, and C districts- (in Japanese), 1999.

[6 ] Riki Therivel and Maria Rosario Partidario, The Practice of Strategic Environmental Assessment, 1996.

[ 7 ] Sachihiko Harashina, "A New Stage of EIA in Japan: Towards Strategic Environmental Assess-

${ }^{1}$ Hiroshi Watanabe, Yoji Takahashi, Satoru Sadohara, Toshio Ojima and Akihiko Mochiduki, "An Evaluation Study on the Building Heat Disposal Pipeline System-An Improvement for Heat Island Problem in Urban Area- (in Japanese)", Papers of the Annual Conference on City Planning, Vol. 37 2002, pp. 1057-1062.

2 Takehiko Mikami, "Actual condition of Urban Heat Islands in Japan (in Japanese)", Environmental Information Science, 32 (3), 2003, pp. 32-36. 
ment”, Built Environment, 27(1), 2001, pp. 8-15.

[8] Sachihiko Harashina, Environmental Impact Assessment (Revised edition): The University of The Air, 2000.

[9] Sachihiko Harashina, Urban Land Use and Growth Management: Environmental Planning for Sustainable Development-A Warning from Tokyo- ; Paper prepared for a panelist at Dialogue 1, Habitat-II, Istanbul, Turkey, June 3-14 (1996) ; Paper published in How Cities Will Look in the 21st Century, HABITAT II Dialogue 1, United Nations Centre for Regional Development, 1996 , pp. 53-60.

[10] Sadler, B. and Verheem, R., Strategic Environmental Assessment, 1996.

[11] Tokyo Metropolitan Government home page http://www2.kankyo.metro.tokyo.jp/assess/index. htm

[12] Tokyo Metropolitan Government, Construction statistics chronology (in Japanese), 2003.

[13] Tokyo Metropolitan Government, Outline of urban planning (in Japanese), 2004. 